ISSN 0976 - 6995 (Print)

ISSN 0976 - 7002 (Online)

Volume 5, Issue 1, January - April (2014), pp. 23-35

(C) IAEME: https://iaeme.com/Home/journal/IJDMT

IJDMT

(C) I A E M E

https://doi.org/10.34218/IJDMT.5.1.2014.30320140501003

\title{
PREDICTIVE MODELLING OF DRILL WEAR: COMPARATIVE ANALYSIS OF ANN AND FUZZY LOGIC TECHNIQUES
}

\author{
Y.D.Chethan ${ }^{1}$, H.V.Ravindra ${ }^{2}$, Shashank.V.Srivatsa ${ }^{3}$, Ashrith.J.G ${ }^{4}$ \\ 1,3, ${ }^{4}$ Dept. of Mechanical Engineering, Maharaja Institute of Technology - Mysore, India \\ ${ }^{2}$ Dept. of Mechanical Engineering, PESCE - Mandya, India
}

\begin{abstract}
Today's fast growing technology has raised the bar when it comes to the accuracy of machined components. The primary objective of this research is to estimate drill wear. In this study, drill wear estimation is carried out by considering Acoustic Emission (AE), Vibration Velocity and Drill Tool Chatter measured using image features obtained by Machine Vision system. In order to identify the tool wear conditions based on the signal measured, an Artificial Neural Network, using a Feed Forward - Back-Propagation algorithm, and Fuzzy Logic approach, have been adopted. The neural network is trained to estimate the average drill wear and after each drilling operation the drill wear is measured with Tool Maker's Microscope. The input parameters that are being used for estimation in this project were found to be non-linearly varying with the desired output. Due to this, the interpretation and prediction of data becomes very difficult. Hence, the two expert systems, i.e., Artificial Neural Network and Fuzzy Logic toolboxes will be used to analyse the best fit model in predicting the output of tool wear for this specific drill job. The prediction accuracy is then compared to analyse which model could give better results so that it can be recommended for machine learning and future work. When ANN and MAMDANI FIS methods were used and the actual tool wear and predicted tool wear were compared, it was observed that ANN produced better correlations and hence it is selected for predictions of tool wear for the present work conditions.
\end{abstract}

Keywords: Drilling, Tool Wear, Artificial Neural Network, Fuzzy Logic, MAMDANI Fuzzy Inference System. 
International Journal of Design and Manufacturing Technology (IJDMT), ISSN 0976 - 6995(Print), ISSN 0976 - 7002(Online) Volume 5, Issue 1, January - April (2014), pp. 23-35 @ IAEME

\section{INTRODUCTION}

Maintenance is an important determinant of industrial productivity. A predictive rather than a reactive maintenance policy is desired as the most effective way of reducing costs due to unexpected failure and stoppage of equipment. Predictive maintenance is based on continuous monitoring of equipment through sensor-based data collection equipment, and specialized technologies to measure specific system variables. Based on a continuous acquisition of signals with multi-sensor systems it is possible to estimate or to classify certain wear parameters by means of neural networks [1]. Condition-based predictive maintenance can be implemented by manufacturing industries to detect faults, troubleshooting and anticipating equipment failure [2]. Successfully implementing a condition monitoring programme allows the machine to operate to its full capacity without having to halt the machine at fixed periods for inspection. Among various methods of condition monitoring acoustic emission monitoring is a better method for the early detection of failure. Acoustic emissions (AE) is the phenomenon of transient elastic wave generation due to a rapid release of strain energy caused by a structural alteration in a solid material under mechanical or thermal stresses. Generation and propagation of cracks, growth of twins etc. associated with plastic deformation is among the primary sources of AE. Hence it is an important tool for condition monitoring through nondestructive testing [3]. The advantage of acoustic emission monitoring over vibration monitoring is that the $\mathrm{AE}$ monitoring can detect the growth of subsurface cracks whereas the vibration monitoring can detect defects only when they appear on the surface.

$>$ Drilling machine tool is one of the most versatile machine tool used in manufacturing industries. The quality of the finished products depends mainly on the stability and rigidity of different machine components of a drilling machine tool. The experimental work consists of drilling a spheroidal graphite (S.G) cast iron block using high-speed steel drill bit. The experiments will be carried by varying the spindle speed and feed. The experimental work involves measuring $\mathrm{AE}$ signal by using $\mathrm{AE}$ measuring system, the vibration velocity from the spindle bearing housings and flank wear (average) will be measured by using machine condition tester T-2000 and tool maker's microscope respectively. Experimental analysis will be carried out to study the AE signal parameters, vibration velocity with machining time for various cutting conditions. Finally, the results will be compared with the experimental results.

Machine Vision is a subfield of engineering that incorporates computer science, optics, mechanical engineering, and industrial automation. Machine vision is the application of computer vision to industry and manufacturing. Manufacturers favour machine vision systems for visual inspections that require high-speed, high-magnification, 24-hour operation, and/or repeatability of measurements. Frequently these tasks extend roles traditionally occupied by human beings whose degree of failure is classically high through distraction, illness and circumstance. However, humans may display finer perception over the short period and greater flexibility in classification and adaptation to new defects and quality assurance policies. Machine vision and computer vision systems are capable of processing images consistently, but computer-based image processing systems are typically designed to perform single, repetitive tasks [4]. Machine vision with a computer based image acquisition systems have successfully been used in the past to measure various parameters related to drilling [5]. 
International Journal of Design and Manufacturing Technology (IJDMT), ISSN 0976 - 6995(Print), ISSN 0976 - 7002(Online) Volume 5, Issue 1, January - April (2014), pp. 23-35 @ IAEME

The input parameters that are being used for estimation in this project were found to be non-linearly varying with the desired output. Due to this, the interpretation and prediction of data becomes very difficult. Hence, the two expert systems, i.e., Artificial Neural Network and Fuzzy Logic toolboxes which have been found to map complex data, [6, 7, 8] will be used to analyse the best fit model in predicting the output of tool wear for this specific drill job. Using such a system, a new methodology is built to compare the experimental results of the acoustic emission, vibration velocity, and tool chatter measured with image features obtained by Machine vision system. Recently, Artificial Neural Networks (ANN's) have been in use to validate the results obtained and also to predict the behaviour of the system (drilling) under any condition within the operating range. The application of neural networks to in-process estimation has attracted great interest. The superior learning, noise suppression and parallel computation abilities are the major advantages of the neural network method [9]. Furthermore, a 2 layer ANN has been used to approximate any non-linear function [10].

Fuzzy logic concept which bases itself on If-Then rules determined by the various membership functions can also be applied to tool wear monitoring, which is based on the already discussed inputs of image features obtained by machine vision system, vibration velocity signal \& acoustic emission signal. It will mainly be used to classify the wear states as three distinct membership functions [11]. These parameters will be given as input and a target, as output, that is the tool wear measured from the Tool Maker's Microscope to the fuzzy logic controller.

\section{EXPERIMENTAL SETUP}

The Experiments are conducted by using all the conditions as stated below. The trials are done with the combination of speed and feed up to twenty one trials for each tool till the wear is seeing with graduation. For every trial, the tool is checked for wear rate and the concordant rate of vibration velocity. At the same time acoustic emission readings and videos are also taken in to account. Videos and photos are meant for machine vision analysis purpose.

The combination of speed 680, 490 and $360 \mathrm{rpm}$ consists of three feeds for each of the three speeds i.e., $0.095,0.19$ and $0.285 \mathrm{rev} / \mathrm{min}$. This corresponds that, for example one speed say $680 \mathrm{rpm}$ will run with $0.095 \mathrm{rev} / \mathrm{min}$ for 21 holes drilled with the same tool and after every hole is drilled, the tool is taken for wear testing. Meanwhile the vibration \& acoustic readings along with complete video of the working conditions are captured.

TABLE 1: DRILL BIT SPECIFICATION

\begin{tabular}{|l|c|}
\hline \multicolumn{1}{|c|}{ Tool material } & High speed steel \\
\hline Diameter of the drill bit used & $10 \mathrm{~mm}$ \\
\hline Chisel edge angle & $125^{\circ}$ \\
\hline Helix angle or Rake angle & $30^{\circ}$ \\
\hline Point angle & $118^{\circ}$ \\
\hline Lip clearance angle & $12^{\circ}$ \\
\hline
\end{tabular}


International Journal of Design and Manufacturing Technology (IJDMT), ISSN 0976 - 6995(Print), ISSN 0976 - 7002(Online) Volume 5, Issue 1, January - April (2014), pp. 23-35 @ IAEME

TABLE 2: CUTTING CONDITIONS

\begin{tabular}{|l|l|}
\hline Machine tool & Automatic drilling machine, model P4/38 \\
\hline Cutting tool & High speed steel drill bit (HSS) \\
\hline Work material & Cast iron \\
\hline
\end{tabular}

TABLE 3: SPEED AND FEED COMBINATION

\begin{tabular}{|c|c|}
\hline Motor (rpm) & Feed $(\mathbf{m m} / \mathbf{r e v})$ \\
\hline \multirow{3}{*}{680} & 0.095 \\
\cline { 2 - 2 } & 0.19 \\
\cline { 2 - 2 } & 0.285 \\
\hline \multirow{3}{*}{490} & 0.095 \\
\cline { 2 - 2 } & 0.19 \\
\cline { 2 - 2 } & 0.285 \\
\hline \multirow{3}{*}{360} & 0.095 \\
\cline { 2 - 2 } & 0.19 \\
\cline { 2 - 2 } & 0.285 \\
\hline
\end{tabular}

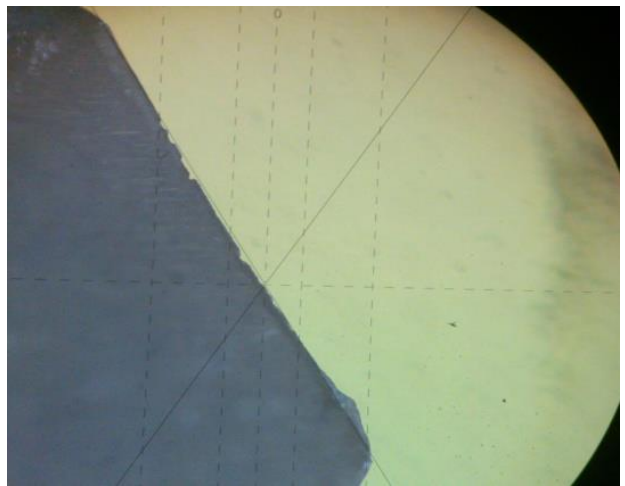

Fig.1: Flank Wear as seen under Tool Makers Microscope

\section{EXPERT SYSTEMS}

\subsection{ARTIFicial NeURAL NeTWORK}

An Artificial Neuron is basically an engineering approach of biological neuron. It has a device with many inputs and one output. ANN consists of a large number of simple processing elements that are interconnected with each other and layered also. Artificial Neural Network also have neurons which are artificial and they also receive inputs from the other elements or other artificial neurons and then after the inputs are weighted and added, the result is then transformed by a transfer function into the output. The transfer function may be anything like Sigmoid, hyperbolic tangent functions or a step.

The simplest artificial neural network has an input layer, hidden layer(s) \& an output layer. The neural network has at least two physical components, namely, the processing elements and the connections between them. The processing elements are called neurons, and the connections between the neurons are known as links. Every link has a weight parameter associated with it. Each neuron receives stimulus from the neighbouring neurons connected to it, processes the information, and produces an output. Neurons that receive stimuli from 
International Journal of Design and Manufacturing Technology (IJDMT), ISSN 0976 - 6995(Print), ISSN 0976 - 7002(Online) Volume 5, Issue 1, January - April (2014), pp. 23-35 @ IAEME

outside the network (i.e., not from neurons of the network) are called input neurons. Neurons whose outputs are used externally are called output neurons. Neurons that receive stimuli from other neurons and whose output is a stimulus for other neurons in the neural network are known as hidden neurons.

There are different ways in which information can be processed by a neuron, and different ways of connecting the neurons to one another. Different neural network structures can be constructed by using different processing elements and by the specific manner in which they are connected.

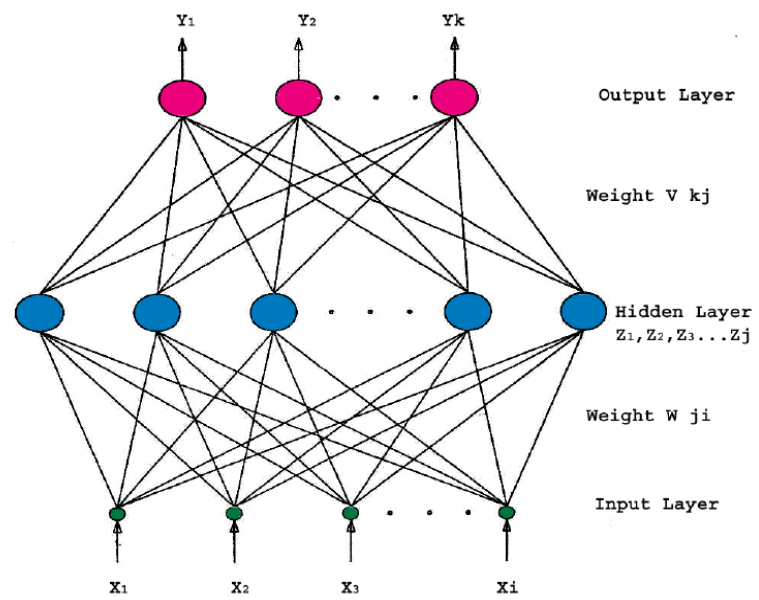

Fig.2: A Simple Neural Network [12]

The standard back propagation method network comprises three layers of processing elements, fully feed forward connected. It comprises the input layer in which all the values of Acoustic Emission, Vibration Velocity and Tool Chatter analysed using image features obtained by Machine Vision are fed. The Hidden layer is that part of the neural network where the estimation or generalization process takes place. Lastly the output layer gathers all the results of the estimation and puts up the results in a presentable format like graphs and pie charts.

All input nodes are connected to all hidden neurons through weighted connections $\mathrm{W}_{\mathrm{ji}}$, and all hidden neurons are connected to all output neurons though weighted connections, $\mathrm{V}_{\mathrm{kj}}$.

The basic equations involved are:

$$
\begin{aligned}
& y_{k}=\sum_{j=1}^{H} U_{k j} z_{j} \ldots . \\
& z_{j}=\frac{1}{1+\exp \left(-n e t_{j}\right)}
\end{aligned}
$$

The least mean square error:

$$
E=\frac{1}{2} \sum_{k=1}^{M}\left(y_{k}-t_{k}\right)^{2} .
$$


International Journal of Design and Manufacturing Technology (IJDMT), ISSN 0976 - 6995(Print), ISSN 0976 - 7002(Online) Volume 5, Issue 1, January - April (2014), pp. 23-35 @ IAEME

The input vector is fed through the network to get an output vector (feed forward process).this is then compared with the output vector and an error is found.

This is then passed back through the neural network (back propagation process) to modify the weights using the following equations:

$$
\begin{aligned}
& \mathbf{V}^{\text {new }}{ }_{\mathbf{k j}}=\mathbf{V}^{\text {old }} \mathbf{k j}_{\mathbf{j}}+\Delta \mathbf{V}_{\mathbf{k j}} \ldots \ldots(\text { Eq } 4) \text { [12] } \\
& \mathbf{W}^{\text {new }}{ }_{\mathbf{j i}}=\mathbf{W}^{\text {old }}{ }_{\mathbf{j i}}+\Delta \mathbf{W}_{\mathbf{j i}} \ldots \ldots \text { (Eq 5) [12] }
\end{aligned}
$$

The gradient descent optimization technique is used to calculate the change in each weight. This is then repeated by picking another random pair of input /output vectors and continuing until the error is a minimum that is the Least Mean square error value should be nearing to zero and Regression value should be nearing to one.

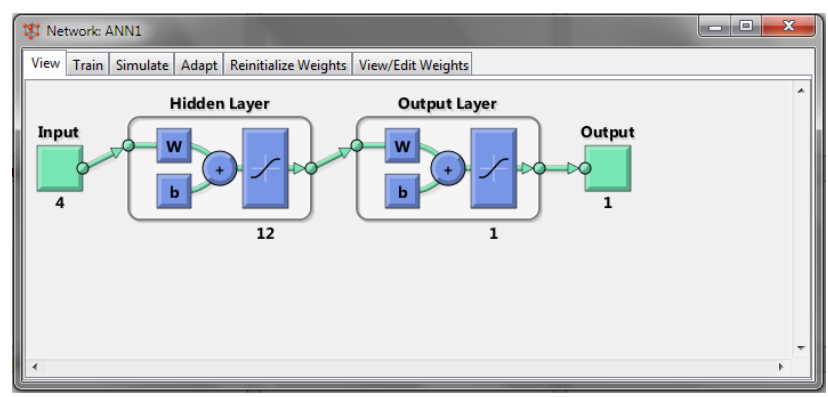

Fig.3: Optimized ANN used for estimation in MATLAB interface (2 Hidden layers and 12 Hidden neurons)

\subsection{FUZZY LOGIC}

It is essential to know the meaning of words fuzzy \& logic. Fuzzy means something which is difficult to perceive clearly or understand and explain precisely or in other words it can be understood to be indistinct or vague. Logic means something that forces a decision apart from or in opposition to reason. Now it is easy to understand the definition of fuzzy logic which states that: Fuzzy logic is a form of knowledge representation suitable for notions that cannot be defined precisely, but which depend upon their contexts.

What makes the Fuzzy Logic Toolbox so powerful is the fact that most of human reasoning and concept formation is linked to the use of fuzzy rules. By providing a systematic framework for computing with fuzzy rules, the Fuzzy Logic Toolbox greatly amplifies the power of human reasoning. Further amplification results from the use of MATLAB and graphical user interfaces.

The Fuzzy Logic Toolbox is a collection of functions built on the MATLAB numeric computing environment. It provides tools to create and edit fuzzy inference systems within the framework of MATLAB, or integrate fuzzy systems into simulations with Simulink, or even build stand-alone $C$ programs that call on fuzzy systems we build with MATLAB. This toolbox relies heavily on graphical user interface (GUI) tools to help to accomplish work, although work can be done entirely from the command line. 
International Journal of Design and Manufacturing Technology (IJDMT), ISSN 0976 - 6995(Print), ISSN 0976 - 7002(Online) Volume 5, Issue 1, January - April (2014), pp. 23-35 @ IAEME

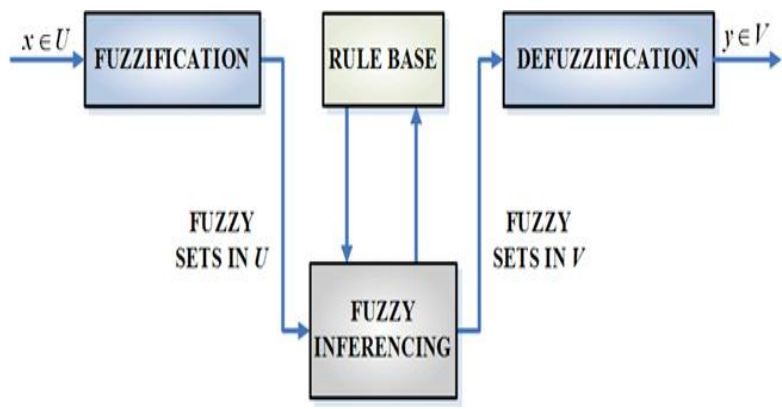

Fig.4: General Fuzzy System

\subsubsection{MAMDANI FUZZY INFERENCE SYSTEM}

Mamdani's fuzzy inference method is the most commonly seen fuzzy methodology. Mamdani's method was among the first control systems built using fuzzy set theory. It was proposed in 1975 by Ebrahim Mamdani as an attempt to control a steam engine and boiler combination by synthesizing a set of linguistic control rules obtained from experienced human operators. Mamdani's effort was based on Lotfi Zadeh's 1973 paper on fuzzy algorithms for complex systems and decision processes. Although the inference process described in the next few sections differs somewhat from the methods described in the original paper, the basic idea is much the same. Mamdani-type inference, as defined for the toolbox, expects the output membership functions to be fuzzy sets. After the aggregation process, there is a fuzzy set for each output variable that needs defuzzification.

Well-known Fuzzy rule-based Inference System is Mamdani fuzzy method. Advantages of the Mamdani fuzzy inference system are:

1. It is intuitive.

2. It has widespread acceptance.

3. It is well suited to human cognition.

Mamdani model can show its legibility and understandability to the laypeople. The Mamdani fuzzy inference system shows its advantage in output expression and is used in this project. To completely specify the operation of a Mamdani fuzzy inference system, it is needed to assign a function for each of the following operators:

1) AND operator for the rule firing strength computation with AND'ed antecedents.

2) OR operator for calculating the firing strength of a rule with OR'ed antecedents.

3) Implication operator for calculating qualified consequent MFs based on given firing strength.

4) Aggregate operator for aggregating qualified consequent MFs to generate an overall output MF.

5) Defuzzification operator for transforming an output MF to a crisp single output value.

Mamdani FIS architecture consists of five layers, output of each layer is the following.

Layer 1: Generate the membership grades $\mu_{\mathrm{A}}, \mu_{\mathrm{B}}$.

$\mathrm{O}_{1, \mathrm{i}}=\mu \mathrm{A}_{\mathrm{i}}(\mathrm{x}), \mathrm{i}=1,2 \ldots . \mathrm{Eq}(5)[13]$ 
International Journal of Design and Manufacturing Technology (IJDMT), ISSN 0976 - 6995(Print), ISSN 0976 - 7002(Online) Volume 5, Issue 1, January - April (2014), pp. 23-35 @ IAEME

$\mathrm{O}_{1, \mathrm{i}}=\mu \mathrm{B}_{\mathrm{i}-2}(\mathrm{y}), \mathrm{i}=3,4 \ldots . \mathrm{Eq}(6)[13]$

The membership function is the generalized bell function

$$
\mu_{A i}(x)=\frac{1}{1+\left[\left(\left(x-c_{i}\right) / d_{i}\right)^{2}\right]^{b i}}
$$

Where $\{\mathrm{bi}, \mathrm{ci}, \mathrm{di}\}$ is the parameter set referred to as premise parameters.

Layer 2:

$$
O_{2, i}=\omega_{i}=\mu_{A i}(x) \times \mu_{B i}(y) i=1,2 \ldots \ldots . \operatorname{Eq}(8)[13]
$$

Firing strength $\omega_{\mathrm{i}}$ is generated with product method.

Layer 3:

$$
O_{3, i}=\overline{\omega_{i}}=\frac{\omega_{i}}{\omega_{1}+\omega_{2}}, i=1,2
$$

Layer4:

$$
O_{4, i}=f_{i}=\overline{\omega_{i} a_{i}} z_{i}, i=1,2
$$

Layer5:

$$
O_{5, i}=\sum f_{i}=\sum \overline{\omega_{i} a_{i}} z_{i}, i=1,2
$$

$\left\{b_{i}, c_{i}, d_{i}\right\}$ are premise parameters and $a_{i}, z_{i}$ are consequent parameters which need to adjust. The type of membership functions (MFs) of the inputs are generalized bell functions, each MF has 3 nonlinear parameters; each consequent MF has 2 nonlinear parameters which are area and centre of the consequent part. Totally, there is 16 parameters in this example. A general M-FIS model can be expressed as in Fig.5.

Rule 1: If $\mathrm{x}$ is $\mathrm{A} 1$ and $\mathrm{y}$ is $\mathrm{B} 1$, then $\mathrm{Z}=\mathrm{C}_{1}$;

Rule 2: If $\mathrm{x}$ is $\mathrm{A} 2$ and $\mathrm{y}$ is $\mathrm{B} 2$, then $\mathrm{Z}=\mathrm{C}_{2}$.

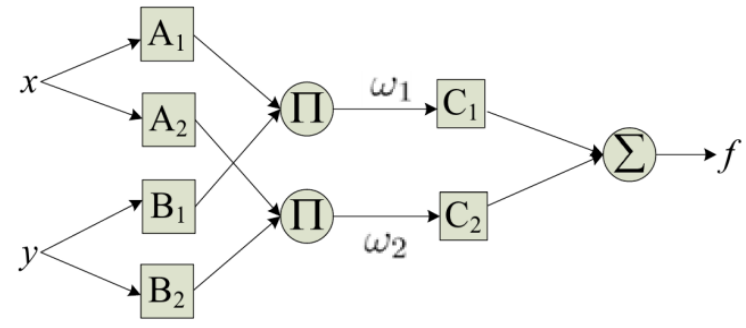

Fig.5: General Model of MAMDANI FIS [13] 
International Journal of Design and Manufacturing Technology (IJDMT), ISSN 0976 - 6995(Print), ISSN 0976 - 7002(Online) Volume 5, Issue 1, January - April (2014), pp. 23-35 ㄷ IAEME

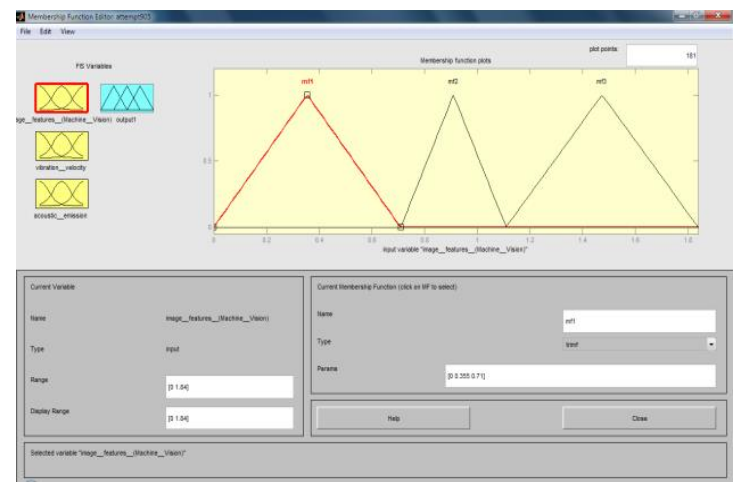

Fig.6: Assigning Membership Functions

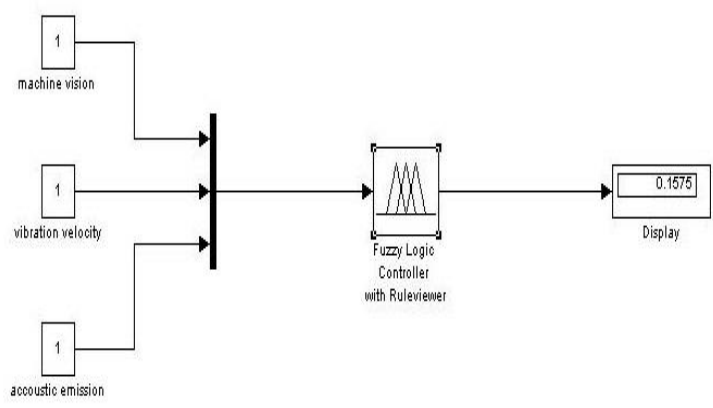

Fig.7: MAMDANI Fuzzy Logic Model

\section{RESULTS AND DISCUSSIONS}

The results of experimental and theoretical analysis are presented in the following tables so that a clear insight can be obtained about the various signals. Functional relationships between the parameters obtained have been shown to derive a basis for a more detailed analysis. Experiments were done for various cutting speeds and feed. Vibration velocity (in $\mathrm{mm} / \mathrm{sec}$ ) at bearing housings along with AE parameter (RMS value in $\mathrm{mV}$ ) were studied. At regular intervals, tool wear was monitored along with the Machine Vision monitoring.

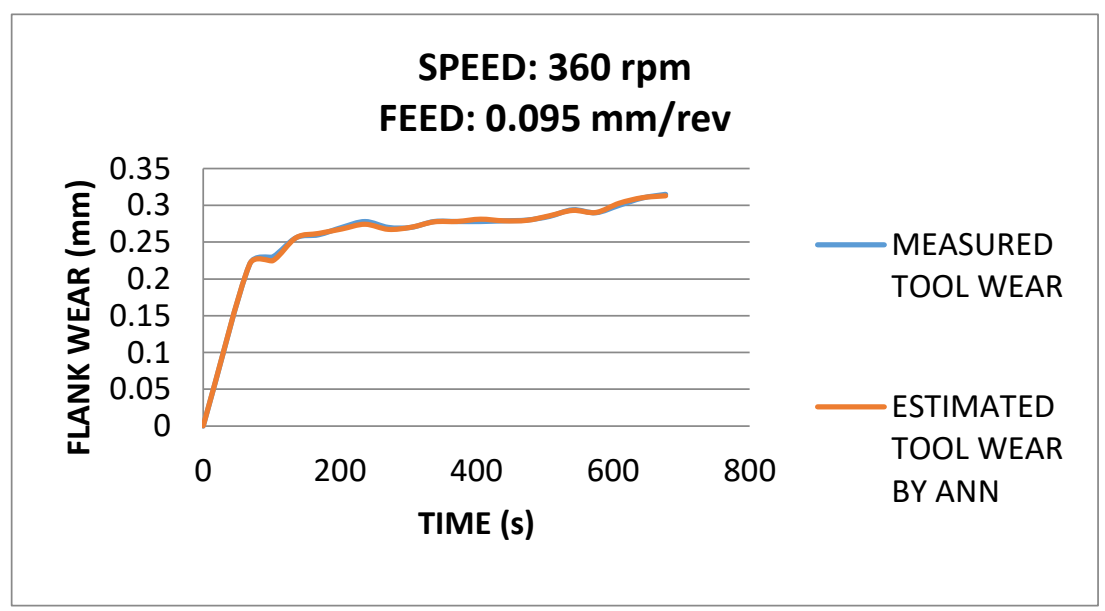

Fig.8: ANN vs. Measured Tool Wear-Set 1 
International Journal of Design and Manufacturing Technology (IJDMT), ISSN 0976 - 6995(Print), ISSN 0976 - 7002(Online) Volume 5, Issue 1, January - April (2014), pp. 23-35 @ IAEME

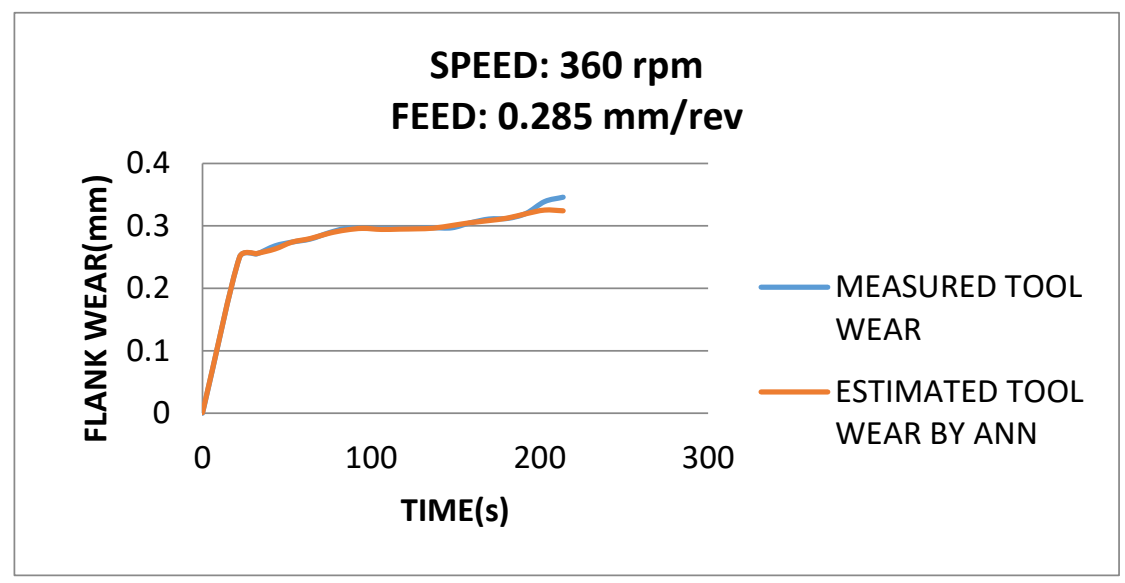

Fig.9: ANN vs. Measured Tool Wear-Set 2

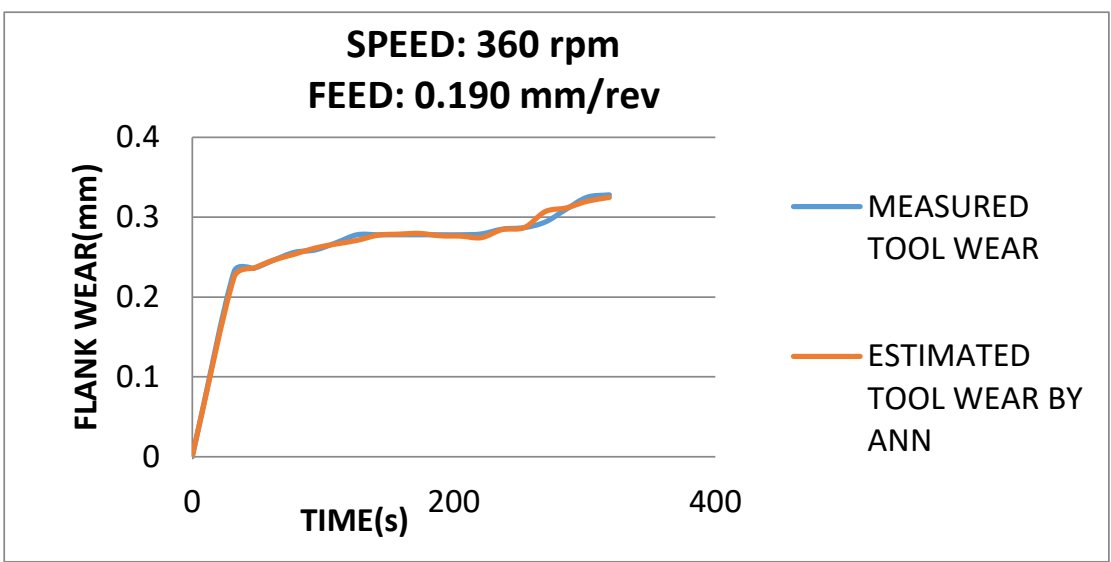

Fig.10: ANN vs. Measured Tool Wear-Set 3

The above figures 8, 9 and 10 indicate Artificial Neural Network estimates of tool wear for various feed rates at $360 \mathrm{rpm}$. It is observed that due to lower magnitude of the parameters, Artificial Neural Network estimates have better correlation at lower cutting conditions.

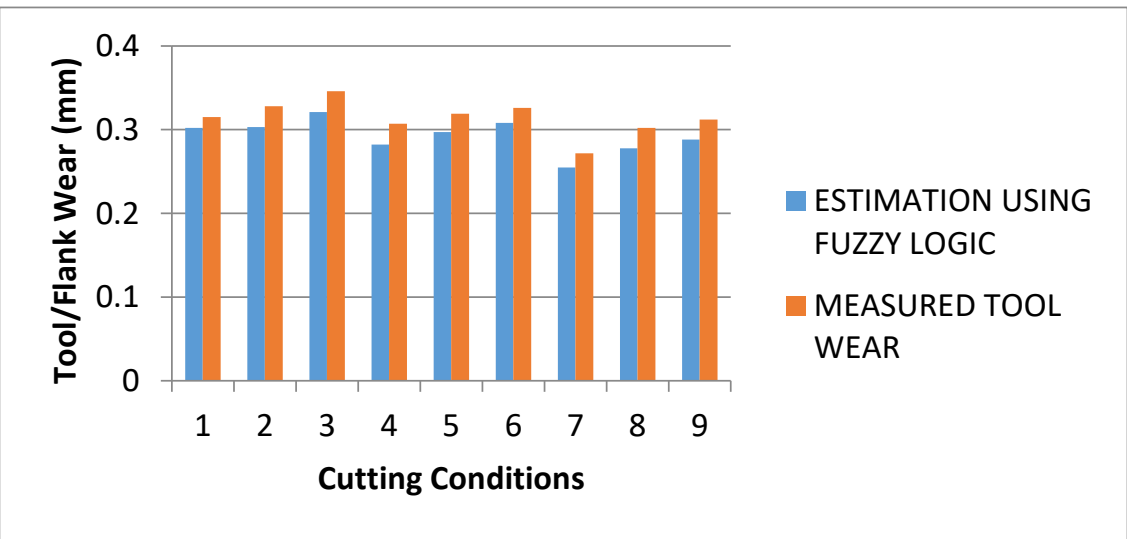

Fig.11: Fuzzy Logic vs. Measured Tool Wear 
International Journal of Design and Manufacturing Technology (IJDMT), ISSN 0976 - 6995(Print), ISSN 0976 - 7002(Online) Volume 5, Issue 1, January - April (2014), pp. 23-35 @ IAEME

Fig.11 shows the comparison between the results obtained from fuzzy logic and measured tool wear and it is inferred that the estimation values of Fuzzy Logic is in good correlation to the measured values of flank wear of the drill tool using Tool Maker's Microscope.

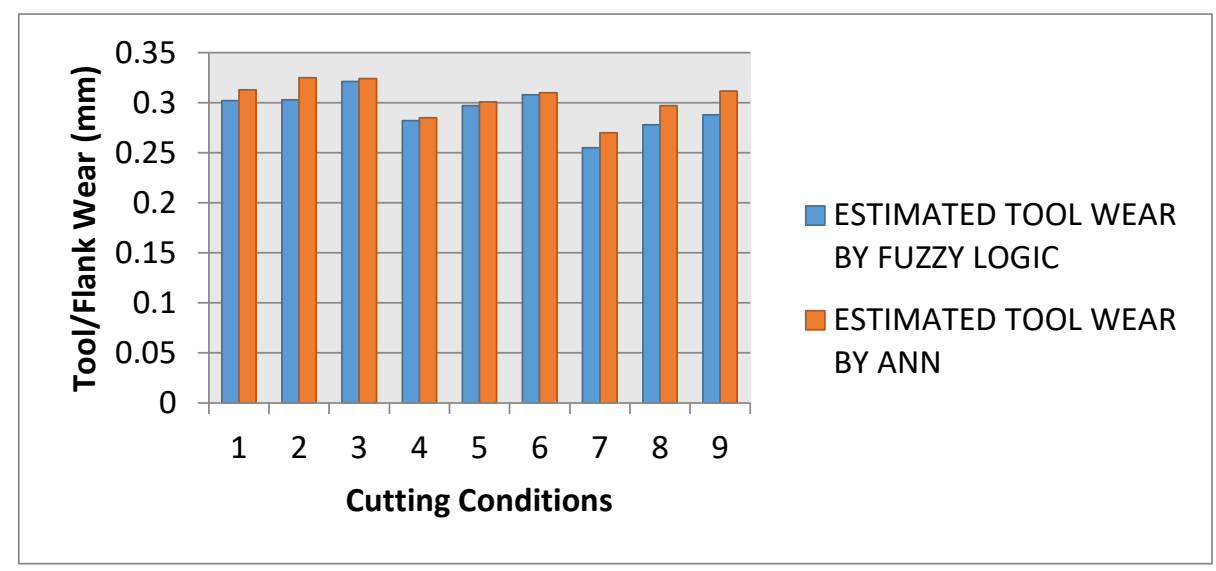

Fig.12: Fuzzy Logic vs. ANN

From Fig. 12 it is inferred that the estimation of drill wear using Fuzzy logic is in close range with that of ANN. It can also be noted that the estimation using ANN is slightly more accurate when compared to the Fuzzy Logic Mamdani method of estimation.

This nature of ANN dominating the 'Mamdani Fuzzy Inference System' method may be due to the fact that in the estimation, only three membership functions have been used (more the membership functions, higher the complexity and longer is the computational time, higher might be the accuracy). Also, the Fuzzy Mamdani Inference system is producing outputs upto three decimal places only. These following factors may have given the neural network an edge over the 'Fuzzy Logic Mamdani Inference System'.

\section{CONCLUSIONS}

In the present study the models on the relationship between the machine signals and the cutting parameters are studied under different tool wear states for drilling machine tool. Experiments were performed by drilling S. G. cast iron block using HSS tool. Experiments were conducted by varying the cutting speed and feed. The drilling operation was interrupted after each drilling operation and the flank wear (average) was measured using toolmaker's microscope. Machine condition tester T-2000 was used to record vibration signals at first spindle bearing housing. AE signal parameter RMS was measured at bearing housing using AE measuring system and image features obtained by Machine Vision system was used to measure tool chatter. Experimental analysis carried out to study the vibration velocity with machining time for various cutting conditions. Finally, the results were analysed with the theoretical analysis to predict the best results.

- For 20 samples of 4 input parameters, 2 hidden layers and 12 hidden neurons were found to produce a Regression Coefficient closer to ' 1 ' and Mean Squared Error closer to ' 0 '. Hence, this particular topology of ANN was found to be feasible.

- For 20 samples of 4 input parameters, comprising of 2 hidden layers and 12 hidden neurons, the 'training' and 'estimation' has generated closer outputs as compared to the Flank wear observed in that of Makers Microscope. 
International Journal of Design and Manufacturing Technology (IJDMT), ISSN 0976 - 6995(Print), ISSN 0976 - 7002(Online) Volume 5, Issue 1, January - April (2014), pp. 23-35 @ IAEME

- Artificial Neural Network estimates have better correlation at lower cutting speed and feed.

- In this study, for the estimation using MAMDANI Fuzzy Inference System, the final values of each of the cutting conditions were considered.

- For each of the 9 cutting conditions, 3 membership functions (Tool chatter measured using Machine vision, Acoustic Emission and Vibration velocity) were given as input to the Fuzzy Logic controller.

- MAMDANI FIS estimates have produced good correlations at low as well as medium cutting speeds and feed.

When ANN and MAMDANI FIS methods were used and the actual tool wear and predicted tool wear were compared, it was observed that, good correlation was obtained for both the methods under various cutting conditions, compared to the actual tool wear.

Among these conditions, both methods showed regularity criterion. It was also observed that they gave better results with corresponding changes in actual tool wear and machining time for lower cutting speed and feed.

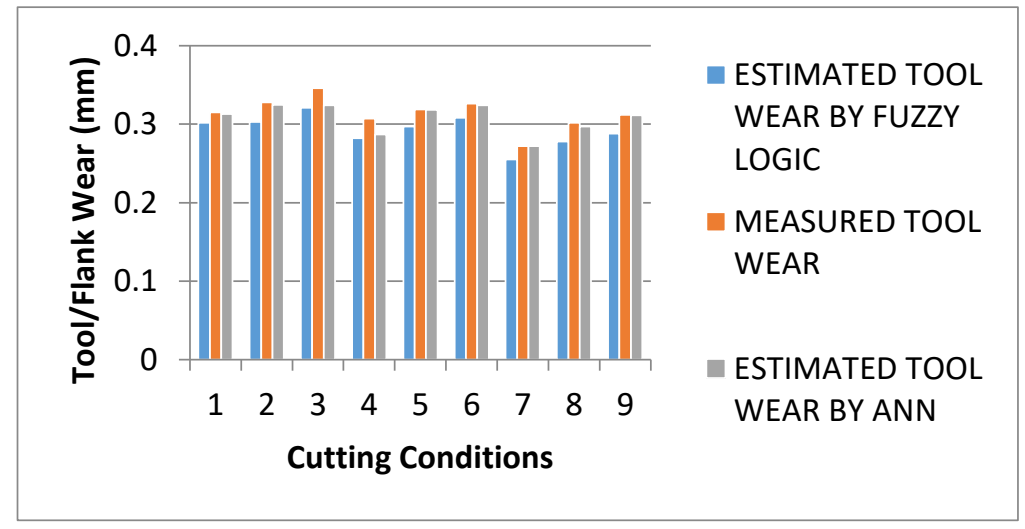

Fig.13: Fuzzy Logic vs. ANN vs. Tool Wear

Thus, for the present work conditions, ANN is the best predictor of tool wear in drilling.

\section{REFERENCES}

[1] Bernhard Sick, On-line and indirect tool wear monitoring in turning with artificial neural networks, University of Passau, Chair of Computer Architectures (Prof. Dr.Ing. W. Grass), Innstr. 33, 94032, Passau, Germany, Mechanical Systems and Signal Processing Vol 16 Issue 4, July 2002.

[2] Pulak Bandyopadhyay ${ }^{1}$, Evers Molina Gonzalez ${ }^{1}$, S.M. $\mathrm{Wu}^{1}$, Ren Huang ${ }^{2}, A$ feasibility study of on-line drill wear Monitoring by DDS methodology, (1) University of Wisconsin-Madison, Madison, Wisconsin 53706, U.S.A. ${ }^{(2)}$ Visiting scholar at UW-Madison from Nanjing Inst. of Technol., People's Republic of China, International Journal of Machine Tool Design an Research, Vol 26, Issue 3, 1986.

[3] H.V. Ravindra ${ }^{a}$, Y.G. Srinivasa ${ }^{\mathrm{b}}$, R. Krishnamurthy ${ }^{\mathrm{b}}$, Acoustic emission for tool condition monitoring in metal cutting, a Department of Mechanical Engineering, PES College of Engineering, Mandya 571401, India, ${ }^{\mathrm{b}}$ Department of Mechanical Engineering, Indian Institute of Technology, Madras 600 036, India, Wear, Vol 212 Issue 1, November 1997. 
International Journal of Design and Manufacturing Technology (IJDMT), ISSN 0976 - 6995(Print), ISSN 0976 - 7002(Online) Volume 5, Issue 1, January - April (2014), pp. 23-35 @ IAEME

[4] C. Bradley, S. Kurada, A machine vision system for tool wear assessment, Department of Mechanical Engineering, University of Victoria, Victoria, BC, Canada V8W 3P6, Tribology Journal Vol.30 Issue 4, April 1997.

[5] JC Su, CK Huang, YS Tarng, An Automated Flank Wear Measurement of Microdrills using Machine Vision - Department of Mechanical Engineering, National Taiwan University of Science and Technology, 43, Keelung Road, Section 4, Taipei 106, Taiwan, ROC, Journal of Materials Processing Technology Volume 180, Issues 1-3, 1 December 2006, Pages 328-335.

[6] Ezugwua, E.O. , Fadera, D.A , Bonneya, J. , Dasilvaa R.B. , and Salesa, W.F. , -Modeling the Correlation between Cutting and Process Parameters in High Speed Machining of Inconel 718 Alloy Using An Artificial Neural Network, International Journal of Machine Tools and Manufacture, Vol.45, pp.1375- 1385, 2005.

[7] Sivarao, Peter Brevern, N.S.M. El-Tayeb \& V.C.Vengkatesh, Neural Network Modeling and Validation for Micro Quality Evaluation in Laser Processing, International Journal of Intelligent Information Technology Application, 2009, 2(2):84-90.

[8] Kovač, p., Rodić, d., Pucovski, v., Mankova, i., Savkovic, b., Gostimirović, m, A review of artificial inteligence approaches applied in intelligent processes, Journal of Production Engineering Vol 15 pp.1 to 6, 2012.

[9] Aydin Salimi, Samira Abasgholizadeh,et al., Using of Artificial Neural Networks to Predict Drill Wear in Machining Process., Dept. of Mechanical Engineering, Islamic Azad University-Maragheh Branch,Iran, Australian Journal of Basic and Applied Sciences, 5(12): 2752-2760, 2011 ISSN 1991-8178.

[10] Nguyen B., and Widrow, B., -Improving the Learning Speed of 2- Layer Neural Networks by Choosing Initial Values of the Adaptive Weights. Proceedings of the International Joint Conference on Neural Networks, Vol. 3, pp. 21-26, 1990.

[11] Fatih Basçiftçi ${ }^{1}$ and Hüseyin Seker ${ }^{2}$. On-line prediction of tool wears by using methods of artificial neural networks and fuzzy logic. ${ }^{1}$ Department of Electronics and Computer Education, Technical Education Faculty, Selcuk University, 42003, Selçuklu, Konya/Turkey, ${ }^{2}$ Master Student of Graduate School of Natural and Applied Sciences, Selcuk University, Konya/Turkey, Scientific Research and Essays Vol. 5(19), pp. 2883-2888, October, 2010.

[12] Kiatcharoenpol, T., \& Karri, V. (2003). An Artificial Neural Network-Based Detection of Wear States in Drilling Operations. In Fourth International Conference on Intelligent Technologies 2003 (InTech'03) (pp. 59-65).

[13] Yuanyuan Chai ${ }^{1}$, Limin $\mathrm{Jia}^{2}$, and Zundong Zhang ${ }^{3}$, Mamdani Model based Adaptive Neural Fuzzy Inference System and its Application, ${ }^{1}$ Candidate for $\mathrm{PhD}$ in the State Key Lab of Rail Traffic Ctrl. and Sfty, and Schl. of Traffic and Transportation, Beijing Jiaotong University, Beijing, 100044 China. ${ }^{2,3}$ Beijing Jiaotong University, World Academy of Science, Engineering and Technology Vol 27, 2009.

[14] T. Prabhu and Mr. A. Arulmurugu, "Experimental and Analysis of Friction Drilling on Aluminium and Copper", International Journal of Mechanical Engineering \& Technology (IJMET), Volume 5, Issue 5, 2013, pp. 130 - 139, ISSN Print: 0976 - 6340, ISSN Online: 0976 - 6359.

[15] Lakhwinder Pal Singh and Jagtar Singh, "Effects of Cryogenic Treatment on the Cutting Tool Durability", International Journal of Design and Manufacturing Technology (IJDMT), Volume 3, Issue 1, 2012, pp. 11 - 23, ISSN Print: 0976 - 6995, ISSN Online: 0976 - 7002. 